\title{
A generic method to assess species exploratory potential under climate change
}

Félix Massiot-Granier, Thibaud Rougier, Patrick Lambert, Juliette Rosebery, Géraldine Lassalle UR EABX, Aquatic Ecosystems and Global Changes Unit, 50 avenue de Verdun, 33612 Cestas-Gazinet, Cedex, France

\section{INTRODUCTION}

$\checkmark$ In response to climate change, some species have shifted their latitudinal and elevational distributions by exploiting new suitable habitats outside of their ranges (Thomas and Lennon, 1999; Parmesan and Yohe, 2003; Cheung et al., 2015)

$\checkmark$ Various studies have demonstrated that species' traits can be important predictors of the type and intensity of responses to climate change (Jiguet et al., 2007; Diamond et al., 2011; Chessman et al., 2013)

$\checkmark$ Build on these conclusions, how can be easily assessed the exploratory potential of species in order to provide insights for biological conservation?

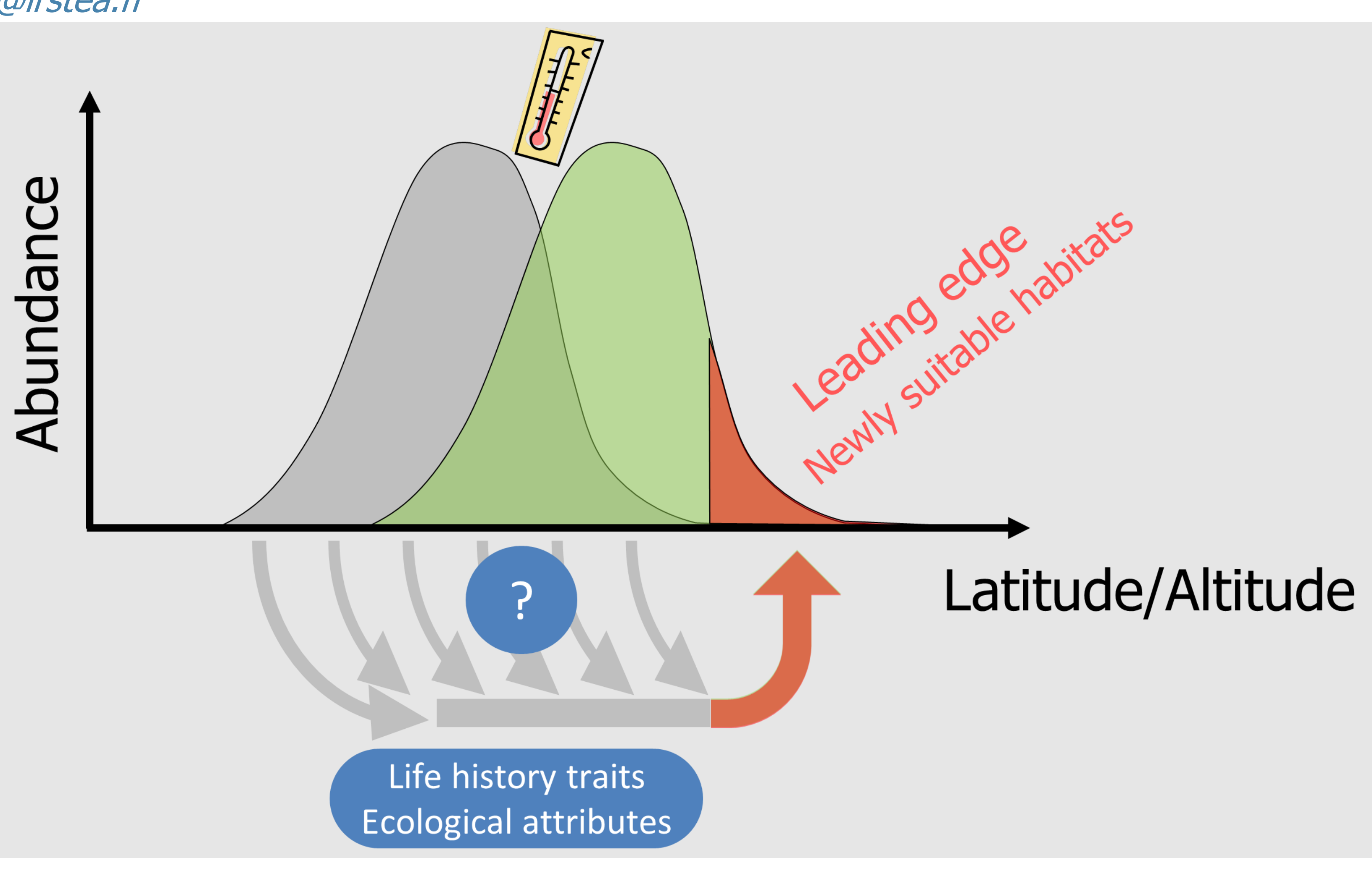

\section{A generic and collaborative approach}

\section{Exploratory potential index}

$\checkmark$ Exploratory potential is there restricted to the capacity of species to reach new suitable habitats, beyond current ranges, apace with the rate of climate change

$\checkmark$ Analytical Hierarchy Process (Saaty, 1980, 2008)

\section{$\checkmark$ Breaks a complex problem down into simplest issues to get relevant experts' opinions $\checkmark$ Combines experts' opinions and observed data into a synthetic metric}

Work plan assigned to taxonomic group of experts

1 Determine the weight of the 3 main criteria (Level II) related to exploration ability using pairwise comparison matrices

2 Determine key life-history traits and ecological attributes (Sub-criteria in level III) relevant for each criterion (e.g body size at maturity, number of reproduction events, homing, distance covered to access feeding grounds ... )

3 Derive weights of each criteria from pairwise comparison matrices

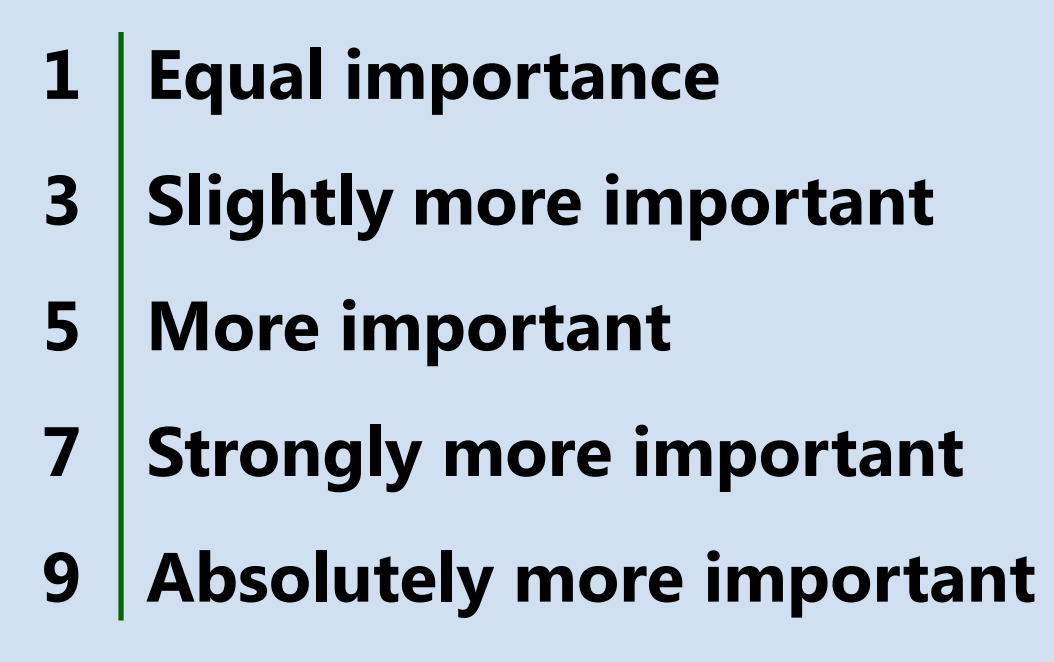

\begin{tabular}{|c|c|c|c|}
\hline & $\begin{array}{c}\text { Life history } \\
\text { trait 1 }\end{array}$ & $-\ldots-\ldots$ & $\begin{array}{c}\text { Life history } \\
\text { trait } n\end{array}$ \\
\hline $\begin{array}{c}\text { Life history } \\
\text { trait 1 }\end{array}$ & 1 & & \\
\hline 1 & & $\cdots$ & \\
\hline $\begin{array}{c}\text { Life history } \\
\text { trait } n\end{array}$ & & & $\cdots$ \\
\hline
\end{tabular}

\section{Data sources}

$\checkmark$ Behavioral, morphological and physiological traits databases coded into ordinal modalities

First case study: diadromous fish species of the Northern Atlantic

Database regarding 24 diadromous fish species $\checkmark$ TraitDiad (Irstea)

$\checkmark$ FishTraits (Frimpong and Angermeier, 2009)


\section{Validation and Perspectives}

\section{Validation}

Compare the species ranking obtained with the exploratory potential index to empirical data, e.g. the range of their (historical) distribution area

Hypothesis: species with a large range that testified of a good post-glacial recolonization should get a high value of exploratory potential index

Compare the species ranking obtained with the exploratory potential index to mono-specific model simulations (Lassalle et al., 2008; Rougier et al., 2014)

\section{Perspectives}

$\checkmark$ Characterize geographic areas in terms of the exploratory potential of their fish assemblages

$\checkmark$ Identify geographic areas hosting species with high or low (extreme) values of exploratory potential and thus of priority for biological conservation and management

A generic tool that could be applied to other taxonomic groups of interest (e.g. micro-organisms, amphibians, birds...) 